\title{
SV40 large $T$ antigen-induced inhibition of terminal differentiation of primary skeletal muscle cells is associated with a block in the expression of MyoD and myogenin
}

\author{
F. A. J. M. Van De Klundert \& H. Bloemendal \\ Department of Biochemistry, Faculty of Science, University of Nijmegen, P.O. Box 9101, NL-6500 HB Nijmegen, \\ The Netherlands
}

Received 29 September 1994; accepted in revised form 12 January 1995

Key words: desmin, myoblast, fusion-defective

\begin{abstract}
Transformation of hamster primary myoblasts with the SV40 large T antigen leads to inhibition of terminal differentiation. This process is associated with a block in the transcription of the muscle-specific determinator genes MyoD and myogenin. The effect of SV40 large T antigen on the terminal differentiation is dominant and cannot be bypassed by re-expression of retrovirally encoded MyoD. The intermediate filament protein desmin is normally up-regulated when myoblasts differentiate into myotubes. Surprisingly, desmin is expressed at relatively high levels in transformed hamster muscle cells grown under proliferative conditions. So desmin expression can be independent of the onset of differentiation. This is in accordance with the expression of the protein in fibroblasts, infected with a MyoD-encoding retrovirus and grown under proliferative conditions, when no other muscle-specific proteins are present.
\end{abstract}

\section{Introduction}

The intermediate filament (IF) protein desmin, which is expressed mainly in skeletal muscle, smooth muscle and heart, is a very early marker of muscle differentiation. At day 8.5 in the development of the mouse, the protein is expressed in the heart rudiment and at day 9.0 post coitum it appears in the myotome [1]. During differentiation of cultured skeletal muscle cells desmin expression is up-regulated to high levels. A certain amount of desmin, however, is already present in replicating myoblasts $[2,3]$. It has now been well established that desmin expression is regulated by myogenic determination factors like MyoD, myogenin, myf-5 and MRF-4 [4-6]. These experiments have all been performed in tissue culture. Despite all the available data on expression regulation, the function of desmin in differentiated muscle cells in vivo remains totally elusive.

It has been suggested recently that desmin expression is a prerequisite for myoblasts to fuse into mult- inucleated myotubes [7]. On the other hand several reports indicate that cells expressing a high amount of desmin but no MyoD and myogenin are incapable of fusion $[8,9]$. Lack of fusion and absence of functional MyoD and myogenin has often been observed after transfection with oncogenes [10-12] or the addition of exogenous growth factors [13, 14]. Also cellular transformation by SV40, polyoma and adenoviruses has been reported to inhibit terminal differentiation [15-19].

In the case of SV40 large $\mathrm{T}$ antigen conflicting results have been reported concerning the inhibitory effect on terminal differentiation $[9,20]$. Therefore, we have transfected primary hamster muscle cells with a plasmid encoding the large $T$ transcription unit. Several resulting clones have been tested for differentiative abilities in correlation with desmin expression. We have found high amounts of desmin protein but no myotube formation. Next, the expression of the muscle-specific proteins MyoD and myogenin has been investigated in some of the cell clones and we 
were not able to detect their mRNAs. By infecting a representative cell line with a $M y o D$ encoding virus we tried to overcome the negative effects of the large $\mathrm{T}$ antigen expression on the terminal differentiation. These experiments contribute to a better understanding of the regulation of desmin expression in relation to myogenesis.

\section{Materials and methods}

\section{Cell culture and DNA transfection}

C2 skeletal muscle myoblast cells [21] and transformed hamster skeletal muscle cells were grown in Dulbecco's modified Eagle's medium (DMEM) supplemented with $20 \%$ fetal calf serum. For induction of myogenic differentiation, confluent cultures were switched to low serum medium (DMEM with $2 \%$ horse serum or $0.4 \%$ ultroser $G$ ). C2 cells are known to fuse within 24 to 36 h.

Transformed hamster skeletal muscle cell lines were established from thigh muscle tissue from a Syrian gold hamster [22]. Tissue was dissociated and the obtained satellite cells were plated into $35-\mathrm{mm}$ tissue culture dishes $\left(10^{5}\right.$ cells per dish) in $2 \mathrm{ml}$ growth medium containing $20 \%$ fetal bovine serum and $2 \%$ chicken embryo extract [23]. After $24 \mathrm{~h}$ cell debris and nonadherent cells were removed by washing with Dulbecco's modified phosphate-buffered saline (DPBS). At this point several cell samples were plated into 100 $\mathrm{mm}$ dishes (at a density of $0.510^{6}$ cells per dish) for transfection with an expression plasmid encoding the SV40 large T antigen and a defective SV 40 origin of replication [24] in order to obtain transformation. Other cell samples were plated in DMEM containing $10 \%$ serum and switched to $2 \%$ horse serum later on for determination of differentiating capacities. Transfection was performed according to a modified calcium phosphate precipitation method [25]. After two weeks in DMEM with 20\% fetal bovine serum and no further supplementations, cell clones containing actively growing cells were isolated and expanded.

Human primary fibroblasts were cultured in DMEM supplemented with $10 \%$ fetal bovine serum. Fibroblasts and tranformed hamster cells were infected with a recombinant retrovirus containing the MyoD coding sequences under the control of a viral long terminal repeat promoter [25]. Cells were selected by supplementation of geneticin, which is a virus-encoded selection marker. After selection, clones were pooled and cells were maintained either in standard growth medium or in differentiation medium for $48 \mathrm{~h}$.

\section{RNA isolation and Northern blotting}

RNA from proliferating C2 myoblasts and 3 day postfusion $\mathrm{C} 2$ myotubes was isolated by the Li-urea method [27]. The same procedure has been applied to three cell clones obtained after transfection with the SV40 plasmid. Total RNA samples $(10 \mu \mathrm{g})$ were glyoxylated, fractionated on $1 \%$ agarose gels and transferred to Hybond N (Amersham). Hybridization was performed with 4 different probes [28]. The complete cDNA probe encoding hamster desmin [29] a 1.5-kb EcoRI myogenin cDNA fragment and a complete MyoD cDNA were labeled according to standard procedures. Total RNA amounts were determined by hybridization with a ribosomal DNA probe.

\section{Immunofuorescent staining and Western blotting}

Indirect immunofluorescent staining procedures were performed on cultured cells as described previously [30]. We used a polyclonal rabbit antibody (poly-des) to chicken gizzard muscle desmin [31] and a monoclonal anti-skeletal myosin (fast twitch) antibody (Sigma). The preparation of cytoskeletal extracts of cultured cells and one-dimensional SDS-gel electrophoresis were described previously [32]. Two Western blots containing 12 different transformed cell lines were incubated with a polyclonal antibody to desmin and a monoclonal antibody to large $T$ antigen (kindly provided by Dr. van der Eb), both followed by an incubation with a peroxidase conjugated second antibody (Nordic). Bands were visualized by incubation in phosphate buffered saline (PBS) with $0.6 \mathrm{mg} / \mathrm{ml}$ 4-chloro1-naphtol (solubilized in ethanol) and $0.6 \mu 1 / \mathrm{ml}$ of a $30 \% \mathrm{H}_{2} \mathrm{O}_{2}$ solution. The same immunodetection procedure has also been used for a Western blot containing $\mathrm{C} 2$ cells and transformed hamster muscle cells grown under proliferative and differentiation promoting conditions.

\section{Results}

After transformation with the origin-defective SV 40 plasmid we have analyzed 12 rapidly growing cell clones for the expression of large $T$ antigen with a monoclonal antibody. The different cell clones express various amounts of large $\mathrm{T}$ antigen (Fig. 1). The same 


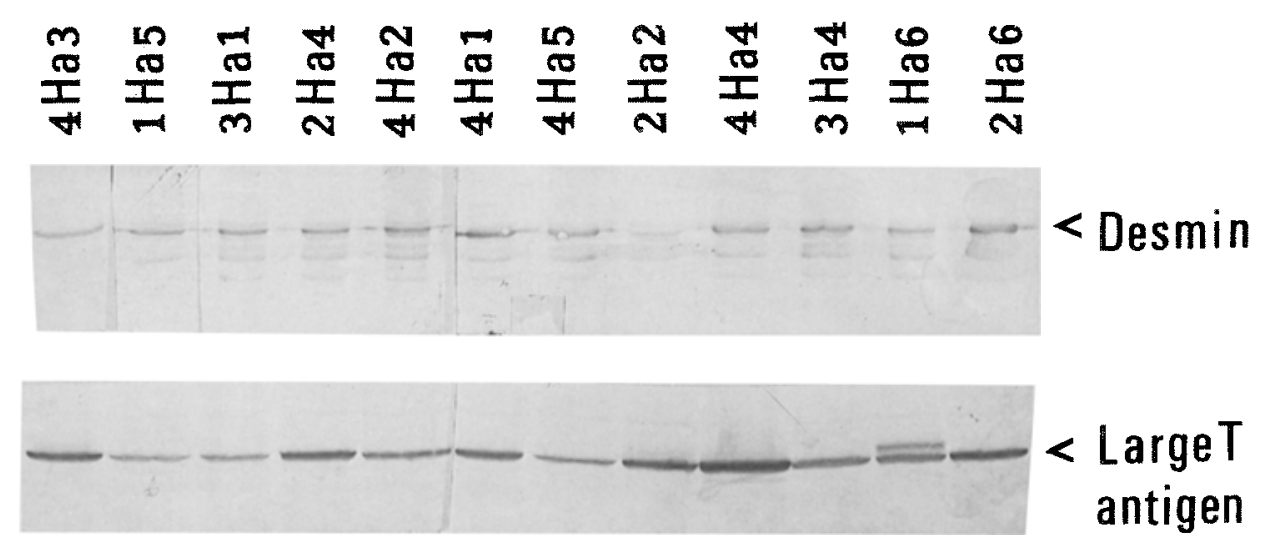

Fig. 1. Western blot analysis of 12 transformed hamster muscle cell lines, using a monoclonal antibody directed against SV40 large $\mathrm{T}$ antigen and a desmin polyclonal antibody.
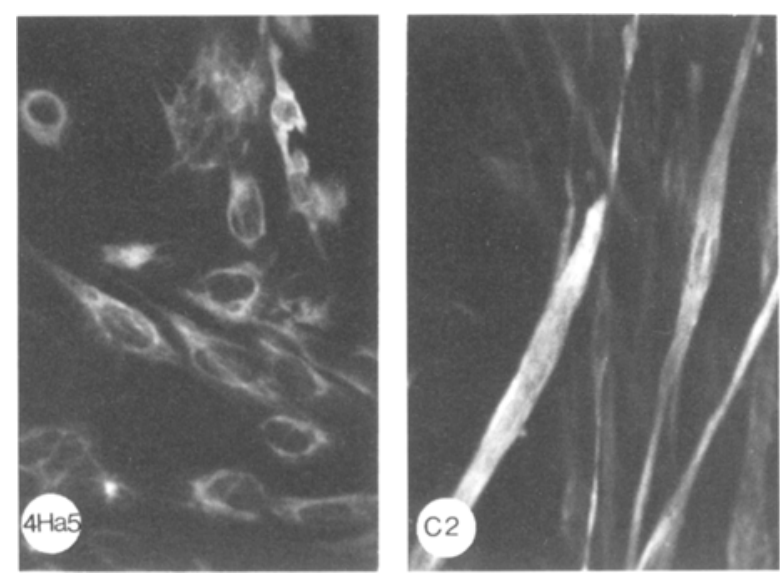

Fig. 2. Phenotype of $\mathrm{C} 2$ cells and $4 \mathrm{Ha} 5$ cells stained with a desmin polyclonal antibody after culturing under differentiative conditions.

cell panel has also been tested for desmin expression using a polyclonal antibody. High amounts of desmin protein have been detected in all cell lines. To induce differentiation, cells originating from each of the 12 different clones and a small cell sample of untransfected primary hamster muscle cells, have been switched to low mitogen medium, immediately after clonal isolation. The untransfected hamster cells showed extensive differentiation into myotubes. Occasionally a few elongated cells with a myotube-like appearance were seen in some of the transformed cell clones. However, no multinucleated myotube formation could be detected. In Fig. 2, cells originating from one of the transformed hamster clones are compared with fully differentiated $\mathrm{C} 2$ myotubes by immunofluorescence staining with a polyclonal desmin antibody. Differentiation tests have been performed at a very early stage. This means that cell clones have been isolated two weeks after transfection and immediately split into two cell samples, one for expansion and one for the differentiation test.

Because of the limited lifespan of the primary hamster muscle cells we have included the mouse cell line $\mathrm{C} 2$ as a control cell line in our experiments. Moreover, the established mouse muscle cell line $\mathrm{C} 2$ is a generally accepted model system for muscle cell differentiation and this cell line has also been used in comparison with fusion-defective muscle cell lines in several other cases [33, 9]. Fusion of $\mathrm{C} 2$ myoblasts into multinucleated myotubes is associated with an elevation of desmin expression. Furthermore, $\mathrm{C} 2$ cells are known to contain myogenic diffentiation markers like MyoD and myogenin. Myogenin is poorly expressed in undifferentiated myoblast cells and becomes highly elevated in multinucleated myotubes. MyoD is expressed in myoblasts and myotubes. Since all cell clones tested gave similar results we only show the Northern blot analysis of one of the transformed clones in comparison with the analysis of $\mathrm{C} 2$ myoblasts and myotubes (Fig. 3A). C2 cells and transformed hamster cells have been analyzed for MyoD, myogenin and desmin mRNA. Desmin is highly expressed under normal conditions (10\% fetal bovine serum) and in low serum medium. Here, howerever, a two-fold decrease can be observed in comparison with the mRNA amounts in cells grown under normal conditions. We do not have an explanation for this phenomenon. As shown in Fig. 3A under high and low serum conditions hardly any MyoD and myogenin could be detected in the transformed hamster cell line. Because we wanted to determine if desmin mRNA levels correlate with protein expression, we have also performed Western blot analysis with a polyclonal desmin antibody (Fig. 3B). We can conclude 
A

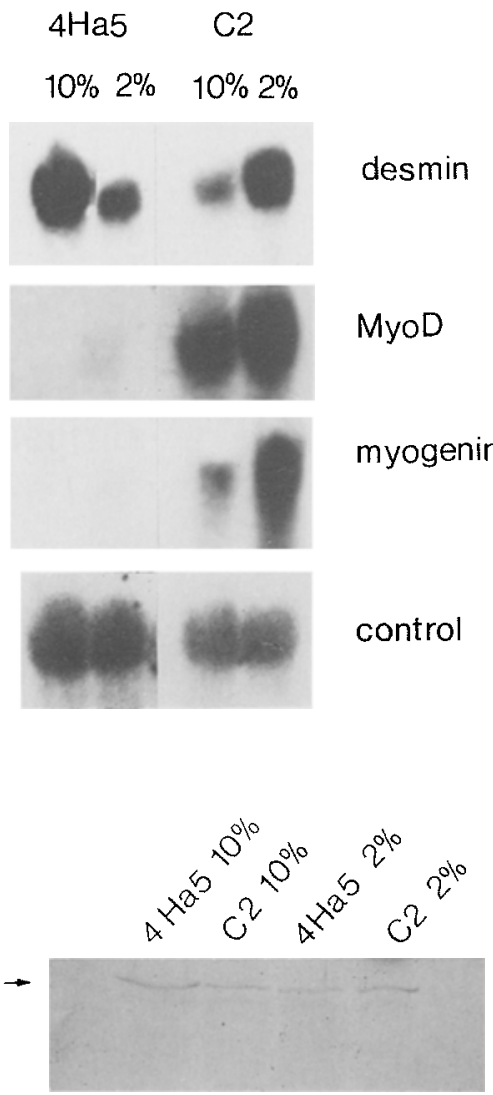

Fig. 3. Northern blot analysis of $4 \mathrm{Ha} 5$ and $\mathrm{C} 2$ cells grown under proliferating ( $10 \%$ fetal bovine serum) and differentiation promoting (2\% horse serum) conditions (A). Northern blots were hybridized with the indicated probes and RNA amounts are approximately equal as detected by hybridization with a ribosomal DNA probe (control). Cells grown under the same conditions were used for Western blot analysis with a monoclonal desmin antibody (B).

from these experiments that desmin protein levels are very similar in hamster muscle cells cultured in medium supplemented with $10 \%$ fetal bovine serum or $2 \%$ horse serum, although mRNA levels are approximately 2-fold lower under low serum conditions.

To compare the primary conditions for desmin expression in different cell types, we have infected human fibroblasts with a retrovirus where MyoD coding sequences are governed by a viral LTR (long terminal repeat) promoter. Infected cells can be selected because the retroviral DNA also encodes the G418 resistance gene. In this way up to $30 \%$ of the cells express MyoD, like has been shown for several nonmuscle cell types, where retrovirally encoded MyoD leads to differentiation along the myogenic lineage $[26$,

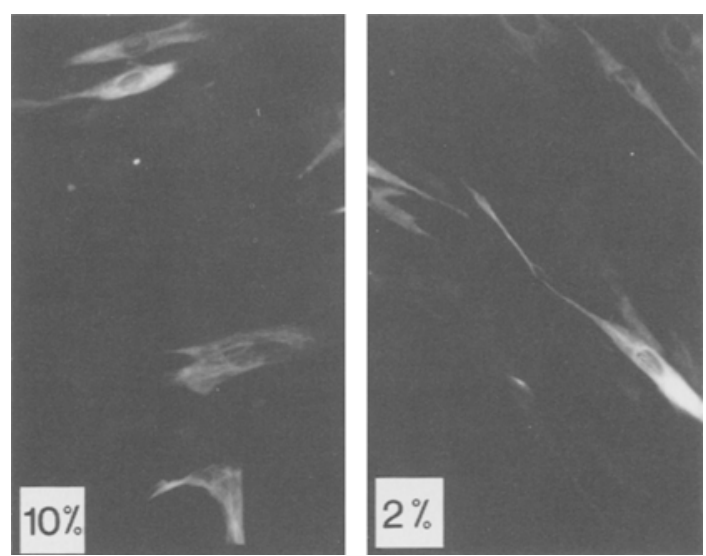

Fig. 4. Human fibroblasts infected with a retrovirus encoding MyoD were grown exponentially ( $10 \%$ fetal bovine serum) and under differentiation promoting conditions ( $2 \%$ horse serum) and incubated with a polyclonal desmin antibody. Desmin-positive cells are detected under both culturing conditions.

34]. It is reported earlier that for this differentiation step forced expression of MyoD must be followed by withdrawal from the cell cycle. We have observed desmin expression in cells cultured under proliferative and differentiative conditions (Fig. 4). Therefore, $\mathrm{MyoD}$ expression alone is sufficient for induction of the desmin gene in cells which are normally desminnegative.

The retroviral infection procedure has also been applied to investigate whether differentiation can proceed in fusion-incompetent hamster cells by forced expression of MyoD. After selection, the cells have been switched to differentiation medium and immunofluorescence tests have been performed for the detection of the terminal differentiation marker fast-twitch skeletal myosin. We have never observed myotube-like cells after infection with the MyoDencoding virus followed by selection by geneticin and either no myosin protein could be detected in selected hamster muscle cells. On the other hand in differentiated C2 myotubes myosin expression was clearly visible (results not shown). This indicates that desmin can be expressed independent of the expression of MyoD and myogenin. The large $\mathrm{T}$ antigen block can, in this case, not be bypassed by re-expression of MyoD.

\section{Discussion}

We have shown that primary muscle satellite cells transfected with the transcription unit of SV40 large 
$T$ antigen do not conform to terminal differentiation anymore. Previous reports largely describe the transfection of established muscle cell lines with transforming genes such as ras, jun, myc and E1A [10, 12, 11, 35]. All our isolated cell clones were growing exponentially and continued to express desmin. We have performed Northern blot analysis with a few clones for detection of MyoD and myogenin mRNA expression. Although desmin expression levels were comparable in $\mathrm{C} 2$ muscle cells and transformed hamster cells, no MyoD and myogenin mRNA could be detected.

Activated Ras and excess Fos have been shown to prevent terminal differentiation [10], by interfering with MyoD expression. Another possible mechanism is provided by the direct interaction of $M y O D$ with the leucine zipper of c-Jun. In the case of excess c-Jun, cell growth is favored instead of cellular differentiation. Recently new information in this respect has been provided by experiments concerning the retinoblastoma gene product. This protein in its unphosphorylated form is proven to be important for withdrawal from the cell cycle during myogenesis [36]. Cell cycle withdrawal can be prevented by binding of the SV40 large T antigen to the retinoblastoma protein. Although MyoD also has the ability to cause growth arrest upon expression in cell lines transformed by oncogenes [37], the SV40 large $T$ antigen demonstrates a dominant effect over MyoD by reversing the cell cycle block.

The absence of MyoD and myogenin may contribute to the lack of differentiation in our transformed hamster muscle cells. There are indications that $\mathrm{MyOD}$ may be more important in this respect because $\mathrm{BC}_{3} \mathrm{H} 1$ cells, which do express myogenin but no MyoD, are fusion incompetent. In this case the block can be overcome by exogenous expression of MyoD [33]. Retrovirally encoded MyoD cannot induce terminal differentiation in our transformed muscle cells. This means that inhibition of terminal differentiation by activated Ras and by overexpressed Fos operates via a different mechanism. This conclusion can be drawn because MyoD expression did result in re-expression of markers associated with terminal differentiation in the case of Ras and Fos [10].

The above evidence indicates that desmin expression is not totally dependent on the expression of $\mathrm{MyOD}$ and myogenin. Cells in a highly proliferative state, represented by the transformation with large $\mathrm{T}$ antigen, are still able to express the early differentiation marker desmin. This is in agreement with the results obtained with the MyoD-infected fibroblasts where desmin expression can be detected in cells cultured in high mitogen medium.

\section{Acknowledgements}

The authors are grateful to Dr. H. Weintraub and Dr. $\mathrm{E}$. Olson for the MyoD-encoding retrovirus, the $\mathrm{MyoD}$ probe and the myogenin probe. We also like to thank Dr. F. Ramaekers for the desmin antibodies, Dr. T. van Kuppevelt for the myosin monoclonal antibody and A. Oosterhof for culturing of the primary hamster skeletal muscle cells.

\section{References}

1. Schaart G, Viebahn C, Langmann H \& Ramaekers F (1989) Development 107: 585-596

2. Pieper FR, Slobbe RL, Ramaekers FCS, Cuypers HT \& Bloemendal H (1987) EMBO J. 6: 3611-3618

3. Li ZL, Paulin D (1991) J. Biol. Chem. 266: 6562-6570

4. Li H \& Capetanaki Y (1993) Nucleic Acids Res. 21: 335-343

5. Li Z \& Paulin D (1993) J. Biol. Chem. 268: 10403-10415

6. Klundert van de FAJM, Jansen HJ \& Bloemendal H (1994) J. Biol. Chem. 269: 220-225

7. Li H, Choudhary SK, Milner DJ, Munir MI, Kuisk IR \& Capetanaki Y (1994) J. Cell Biol. 124: 827-841

8. Grossi M, Calconi A \& Tatò F (1991) Oncogene 6: 1767-1773

9. Haider SR, Wang W \& Kaufman SJ (1994) Exp. Cell Res. 210: 278-286

10. Lassar AB, Thayer MJ, Overell RW \& Weintraub H (1989) Cell 58: 659-667

11. Miner JH \& Wold BJ (1991) Mol. Cell. Biol. 11: 2842-2851

12. Su H, Bos TJ, Monteclaro FS \& Vogt PK (1991) Oncogene 6: $1759-1766$

13. Salminen A, Braun T, Buchberger A, Jürs A, Winter B \& Arnold H-H (1991) J.Cell Biol. 115: 905-917

14. Li L, Chambard J-C, Karin M \& Olson EN (1992) Genes Dev. 6: 676-689

15. Fogel M \& Defendi V (1967) Proc. Natl. Acad. Sci. USA 58: 967-973

16. Yaffe D, and Gershon D (1967) Nature 215: 725-727

17. Graessmann A, Graessmann H \& Fogel M (1973) Dev. Biol. 35: $180-186$

18. Holtzer H, Yeoh BG, Meganathan R \& Kaji A (1975) Proc Natl. Acad. Sci. USA 87: 4051-4055

19. Maione R, Fimia GM \& Amati P (1992) Oncogene 7: 85-93

20. Iujvidin S, Fuchs O, Nudel U \& Yaffe D (1990) Differentiation 43: 192-203

21. Yaffe D \& Saxel O (1977) Differentiation 7: 159-166

22. Yasin R, Beers G, Nurse KCE, Al-Ani S, Landon DN \& Thompson EJ (1977) J. Neurol. Sci. 32: 347-360

23. Benders AAGM, Kuppevelt van THMSM, Oosterhof A, \& Veerkamp JH (1991) Exp. Cell Res. 195: 284-294

24. Gluzman Y, Sambrook JF \& Frisque RJ (1980) Proc. Natl. Acad. USA 77: 3898-3902

25. Klundert van de FAJM, van Eldik GJ, Pieper FR, Jansen HJ and Bloemendal H (1992) Gene 122: 337-343 
26. Weintraub H, Tapscott SJ, Davis RL, Thayer MJ, Adam MA, Lassar AB \& Miller AD (1989) Proc. Natl. Acad. Sci. USA 86: $5434-5438$

27. Auffray C \& Rougeon F (1980) Eur. J. Biochem. 107: 303-314

28. Church, GM and Gilbert W (1984) Proc. Natl. Acad. Sci. USA 81: 1991-1995

29. Raats JMH, Henderik JBJ, Verdijk M, van Oort FLG, Gerards WLH, Ramaekers FCS \& Bloemendal H (1991) Eur. J. Cell Biol. 56: 84-103

30. Krimpenfort PJ, Schaart G, Pieper FR, Ramaekers FC, Cuypers HT, van de Heuvel RM, Vree Egberts WT, van Eys GJ, Berns A \& Bloemendal H (1988) EMBO J. 7: 941-947

31. Rarnaekers FCS, Verheyen RHM, Moesker O, Kant A, Vooys GP \& Herman CJ (1983) Am. J. Surg. Pathol. 7: 381-385
32. Broers JLV, Carney DN, Klein Rot M, Schaart G, Lane EB, Vooys GP \& Ramaekers FCS (1986) J. Cell. Sci. 83: 37-60

33. Choi J, Costa ML, Mermelstein CS, Chagas C, Holtzer S \& Holtzer H (1990) Proc. Natl. Acad. Sci. USA 87: 7788-7992

34. Webster KA, Muscat GEO, Kedes L (1988) Nature 332; 553 557

35. Gu W, Schneider JW, Condorelli G, Kaushal S, Mahdavi V \& Nadal-Ginard B (1993) Cell 72: 309-324

36. Crescenzi M, Fleming TP, Lassar AB, Weintraub \& Aaronson SA (1990) Proc. Natl. Acad. Sci. USA 87: 8442-8446

37. Brennan TJ, Edmondson DG \& Olson EN (1990) J. Cell Biol. 110: 929-937 